\title{
SECAGEM DA MICROALGA Spirulina platensis POR JANELA DE REFRATÂNCIA
}

\author{
T. C. SILVA, C. G. MIRANDA, A. C. F. OLIVEIRA, N. C. SILVA \\ e M. A. S. BARROZO \\ Universidade Federal de Uberlândia, Faculdade de Engenharia Química \\ E-mail para contato: thaise.c_s@ @hotmail.com
}

\begin{abstract}
RESUMO - Entre vários microrganismos já estudados para alimentação funcional, a microalga Spirulina platensis é considerada promissora devido ao seu alto teor de proteínas, vitaminas e minerais, além da presença de compostos bioativos importantes como fenólicos, flavonoides e a ficocianina. Por ter elevado teor de umidade, torna-se necessário utilizar métodos de secagem para garantir que não ocorra degradação da biomassa dessa microalga durante $o$ armazenamento. Nesse sentido, este trabalho avaliou a secagem da Spirulina pelo método de Janela de Refratância, que é uma recente técnica de remoção de umidade que tem se destacado pelo curto tempo de exposição do material a temperaturas relativamente baixas, o que favorece a retenção dos compostos bioativos, tornando-se uma alternativa simples e eficiente para gestão de tal material. Observou-se que essa metodologia de secagem se mostrou satisfatória na remoção da umidade da microalga e que a temperatura utilizada no processo impactou diretamente nos teores de compostos bioativos presentes no produto final.
\end{abstract}

\section{INTRODUÇÃO}

Atualmente, a preocupação com a saúde relacionada a alimentação tem sido um dos pontos fortes das pesquisas científicas. Dentre os alimentos funcionais, a microalga Spirulina platensis tem recebido muita atenção devido ao seu alto potencial nutritivo. A diversidade biológica e farmacológica desta microalga tornou mais popular o seu consumo como suplemento nutricional terapêutico. Além disso, ela é qualificada pelo elevado teor de proteína de boa qualidade além de ser rica em vitaminas, minerais e outros componentes benéficos para a saúde tais como compostos fenólicos, dentre eles os flavonoides, e pigmentos antioxidantes como a ficocianina (Mani et al., 2008).

Entretanto, esta microalga também se caracteriza por ter elevada umidade e diante disso torna-se necessária a aplicação de uma técnica de secagem para conservação do material e posterior utilização como alimento. Dentre os métodos mais inovadores de secagem, pode-se citar o uso da Janela de Refratância. Esta técnica consiste em espalhar o material úmido sobre um filme plástico, o qual está em contato na parte inferior com água quente proveniente de um reservatório. Assim, a energia térmica para a secagem, oriunda da água quente, é transferida para o filme, que é relativamente transparente à radiação infravermelha e chega ao material que desidrata de forma mais uniforme e em temperaturas mais baixas que as 
utilizadas em métodos convencionais, permitindo a retenção de compostos bioativos (Nindo \& Tang, 2007; Zotarelli et al., 2015).

Desse modo, o objetivo desse trabalho foi realizar a desidratação da microalga Spirulina platensis utilizando um secador de Janela de Refratância em diferentes condições de operação, tendo em vista a qualidade final do material no que se refere às mudanças no conteúdo dos compostos bioativos fenólicos, flavonoides, ácido cítrico e fícocianina.

\section{MATERIAL E MÉTODOS}

\subsection{Material Utilizado}

A microalga Spirulina platensis foi fornecida pela empresa Brasil Vital, localizada na cidade de Anápolis, no Estado de Goiás. As amostras foram armazenadas em sacos de polietileno, envoltos em papel alumínio e congeladas em freezer até o momento dos experimentos.

\subsection{Aparato Experimental}

A secagem da microalga foi realizada em um equipamento operando por batelada construído na própria FEQUI/UFU e utilizando como referência o dispositivo empregado por Zotarelli et al. (2015), conforme mostrado na Figura 1.

Figura 1 - Aparato Experimental: Spirulina (a) e Secador por Janela de Refratância (b)
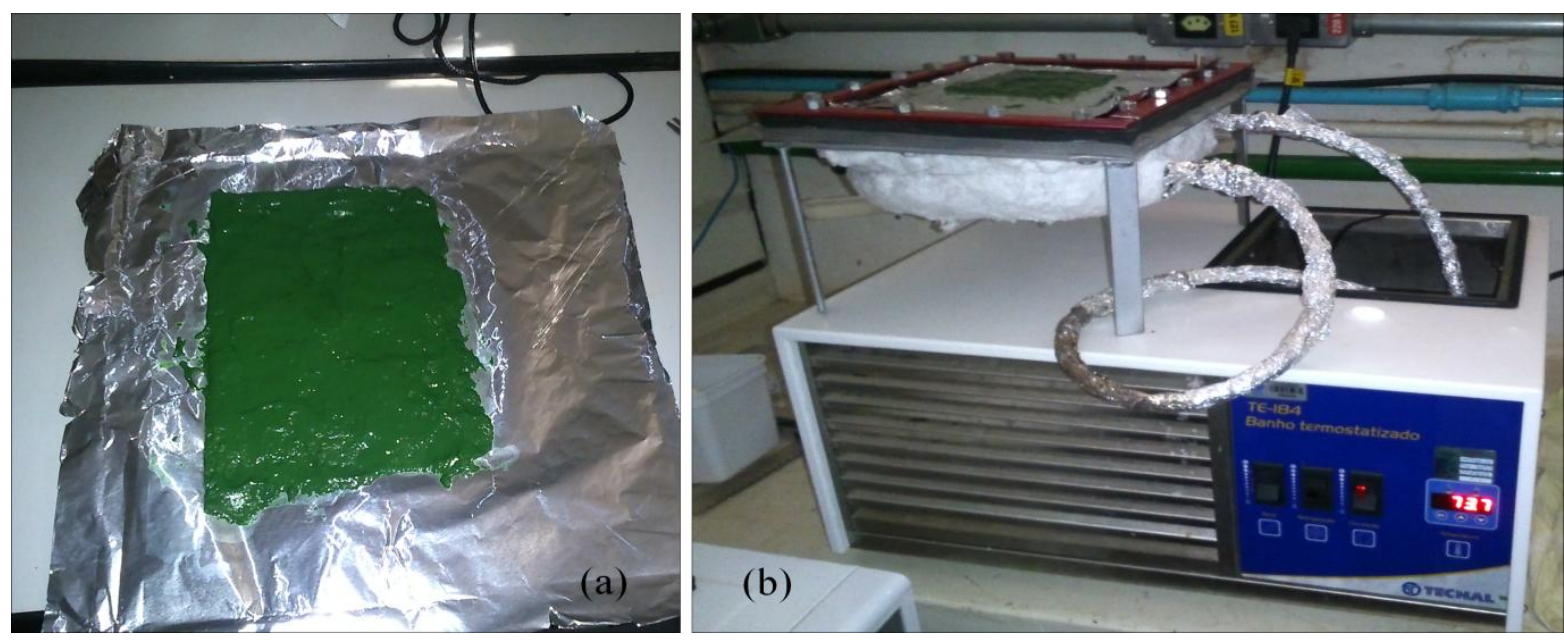

Tal secador consistiu de um pequeno reservatório de aço inox com água quente circulante, proveniente de um banho termostático. O filme plástico utilizado foi o Mylar (Dupont, USA), que foi fixado no topo do reservatório, de maneira que sua face inferior ficasse em contato direto com a água quente circulante e a face superior tivesse contato com a amostra. Para cada experimento, utilizou-se cerca de 40 gramas de Spirulina, que foram uniformemente espalhadas sobre uma folha de papel alumínio para evitar que a amostra grudasse sobre o filme, formando uma camada de cerca de $0,2 \mathrm{~cm}$ de espessura. As variáveis analisadas foram a temperatura da água que alimentava o sistema e o tempo de secagem. 
Assim, realizou-se sete experimentos nas seguintes condições: $6^{\circ} \mathrm{C}$ e $3 \mathbf{~ h} ; 6^{\circ} \mathrm{C}$ e $6 \mathbf{~ h} ; 7^{\circ} \mathrm{C}$ e $2,4 \mathrm{~h} ; 7^{\circ} \mathrm{C}$ e $4,5 \mathrm{~h} ; 70^{\circ} \mathrm{C}$ e $6,6 \mathrm{~h} ; 80^{\circ} \mathrm{C}$ e $3 \mathrm{~h}$ e $80^{\circ} \mathrm{C}$ e $6 \mathrm{~h}$.

\subsection{Análises Realizadas}

Além da umidade, monitorada através do método da estufa $\left(105^{\circ} \mathrm{C} \pm 3^{\circ} \mathrm{C}\right.$ por 24 horas), e da atividade de água, medida pelo equipamento Lab-Swift AW (Novasina), a microalga in natura (antes da desidratação) e após a secagem passaram por uma série de análises físicoquímicas para avaliar a presença de compostos bioativos.

O Teor de Fenólicos Totais (TPC) foi determinado pelo método de Folin Ciocalteau (Singleton \& Rossi, 1965), usando ácido gálico como padrão de referência e leitura no espectrofotômetro à $622 \mathrm{~nm}$. Foi expresso em mg ácido gálico / $100 \mathrm{~g}$ de amostra em base seca. O Teor de Flavonóides Totais (TFC) foi encontrado através do método colorimétrico descrito por Zhishen et al. (1999), utilizando leitura em espectrofotômetro à $450 \mathrm{~nm}$ e a rutina como padrão. Os resultados foram expressos em mg de rutina / $100 \mathrm{~g}$ de amostra em base seca. A Acidez Total Titulável (ATT) foi determinada através da titulação das amostras com $\mathrm{NaOH}$ padronizado, e expressa em mg de ácido cítrico / $100 \mathrm{~g}$ da amostra em base seca (AOAC, 1995). O Teor de Ficocianina (TF) foi determinado pelo método descrito por Costa et al. (2015) submetendo às amostras a leitura em espectrofotômetro nas absorbâncias de 620 e $652 \mathrm{~nm}$. Os resultados foram expressos em $\mathrm{g}$ ficocianina/ $100 \mathrm{~g}$ em base seca.

\section{RESULTADOS E DISCUSSÃO}

Primeiramente, analisou-se os resultados de umidade e compostos bioativos para a microalga in natura. Foram obtidos os seguintes resultados: Umidade: 82,39 $\pm 0,94 \%$, Teor de Fenólicos (TPC): 252,40 \pm 13,77 mg ácido gálico; Teor de Flavonoides (TFC): 4,83 \pm 0,25 mg rutina ; Acidez: 2173,68 \pm 179,32 mg ácido cítrico ; Teor de Ficocianina (TF): 10,48 \pm 0,51 $\mathrm{g}$ ficocianina (todos por $100 \mathrm{~g}$ amostra em base seca). Observou-se o alto teor de umidade do material, reforçando sua necessidade de secagem, além da presença considerável de compostos bioativos, em especial, a ficocianina.

Tabela 1 - Umidade e Atividade de Água da Spirulina após os experimentos

\begin{tabular}{|c|c|c|c|}
\hline Temperatura $\left({ }^{\circ} \mathbf{C}\right)$ & Tempo (horas) & Umidade (\%) & Atividade de Água (AW) \\
\hline $\mathbf{6 0}$ & 3 & $30,65 \pm 2,16$ & 0,829 \\
\hline $\mathbf{6 0}$ & 6 & $15,60 \pm 0,46$ & 0,577 \\
\hline $\mathbf{7 0}$ & 2,4 & $21,13 \pm 0,51$ & 0,694 \\
\hline $\mathbf{7 0}$ & 4,5 & $12,18 \pm 0,11$ & 0,467 \\
\hline $\mathbf{7 0}$ & 6,6 & $11,76 \pm 0,50$ & 0,418 \\
\hline $\mathbf{8 0}$ & 3 & $8,19 \pm 0,19$ & 0,437 \\
\hline $\mathbf{8 0}$ & 6 & $8,06 \pm 0,20$ & 0,359 \\
\hline
\end{tabular}

Na Tabela 1 estão expostos os resultados obtidos de umidade e atividade de água ao término de cada experimento. Verificou-se que quanto maiores a temperatura e tempo de desidratação, menores foram os teores de umidade e atividade de água obtidos nas amostras. A literatura indica que valores de atividade de água inferiores a 0,6 permitem um armazenamento seguro do material, pois nessa faixa não há o crescimento de micro- 
organismos (Celestino, 2010). Assim, apenas as condições de $60^{\circ} \mathrm{C}-3 \mathrm{~h}$ e $70^{\circ} \mathrm{C}-2,4 \mathrm{~h}$ não foram satisfatórias. Torna-se necessária então a análise do impacto das demais condições experimentais nos compostos bioativos, para determinar a melhor condição operacional.

Os resultados obtidos para os teores de compostos bioativos em comparação com a microalga in natura estão expostos nas Figuras 2, 3, 4 e 5:

Figura 2 - Teor de Fenólicos Totais (TFC) da Spirulina após as secagens e in natura

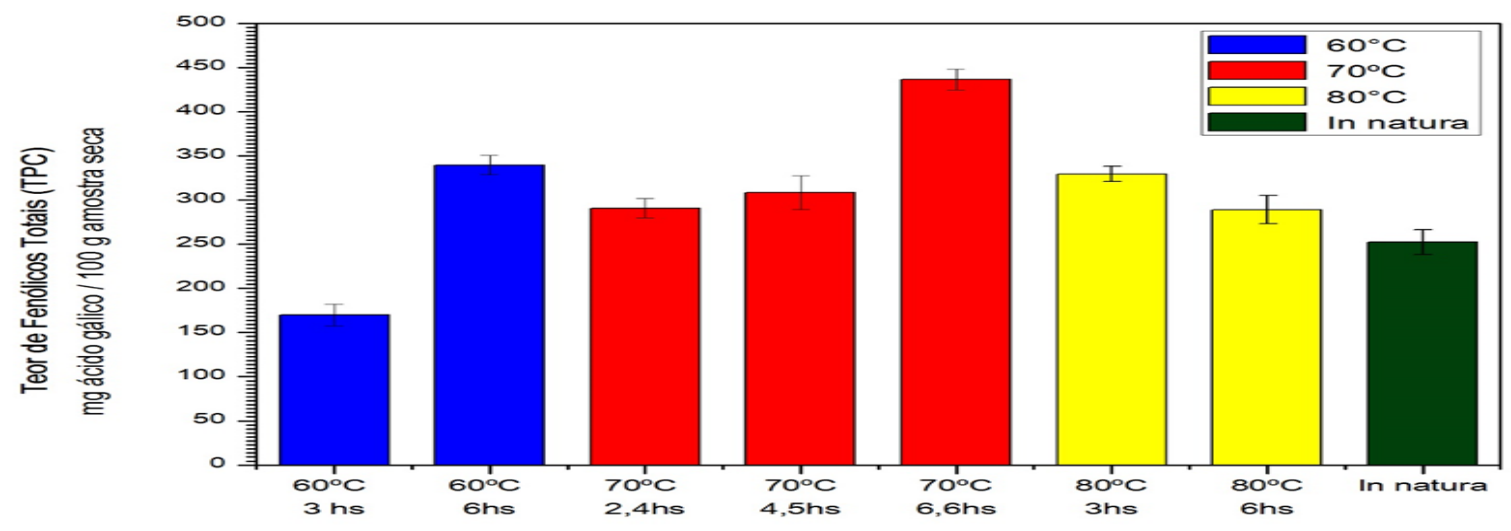

Figura 3 - Teor de Flavonoides Totais (TFC) da Spirulina após as secagens e in natura

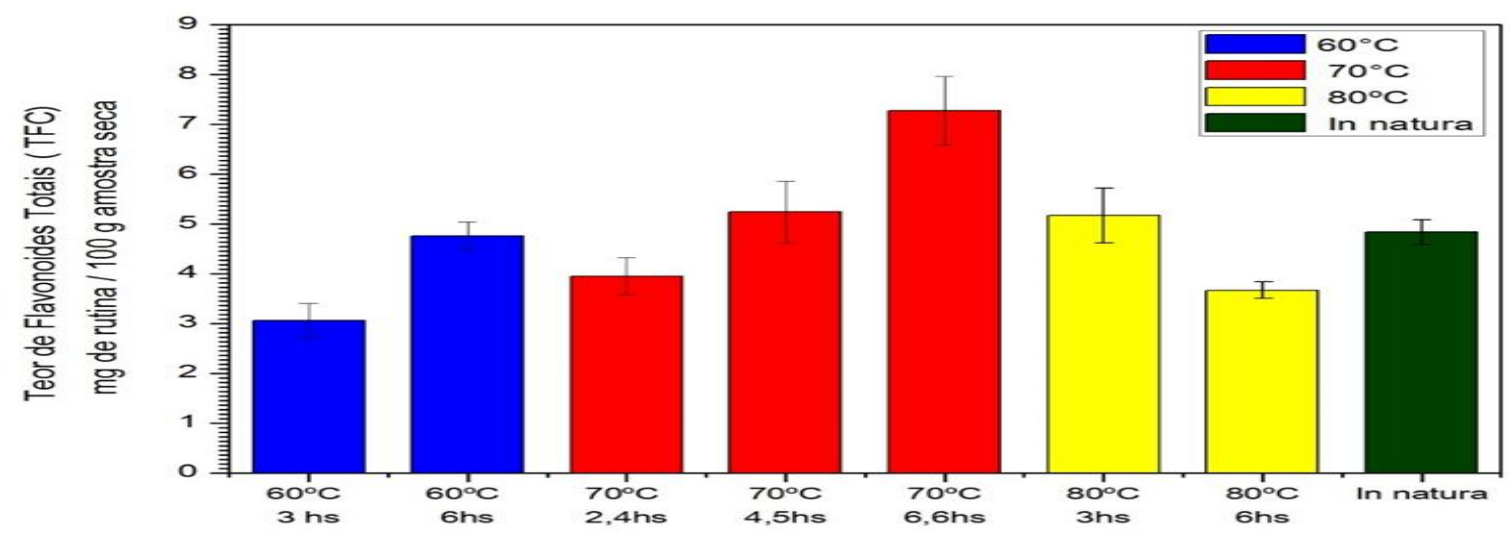

Analisando-se as Figura 2 e 3, observou-se que foi possível obter teores de compostos fenólicos e flavonoides próximos e até mesmo superiores aos da microalga in natura. Tal comportamento tem sido observado em alguns estudos, como relatado por Chism \& Haard (1996) que observaram que certos materiais, quando submetidos à secagem, podem apresentar aumento em seus teores de bioativos devido à liberação dos mesmos da matriz interna do material durante a remoção de umidade, justificado pelo rompimento de estruturas celulares internas que ocorre durante o processo. A exceção para tal comportamento foi verificada nas condições de alta umidade final $\left(60^{\circ} \mathrm{C}\right.$ e $3 \mathrm{~h} ; 70^{\circ} \mathrm{C}$ e $\left.2,4 \mathrm{~h}\right)$ e nas condições de temperatura e tempo mais elevados $\left(80^{\circ} \mathrm{C}\right.$ e $\left.6 \mathrm{~h}\right)$ onde a exposição térmica foi maior e os teores de bioativos menores. Em ambos os compostos, a melhor condição operacional observada foi à $70^{\circ} \mathrm{C}$, indicando essa temperatura como a mais favorável para os teores finais de fenólicos e flavonoides. Nessa temperatura, o tempo também apresentou impacto positivo, sendo que o 
experimento realizado a $70^{\circ} \mathrm{C}$ e $6,6 \mathrm{~h}$ de secagem foi visivelmente a melhor condição dentre as analisadas para esses compostos bioativos.

Figura 4 - Teor de Acidez Total (ATT) da Spirulina após as secagens e in natura

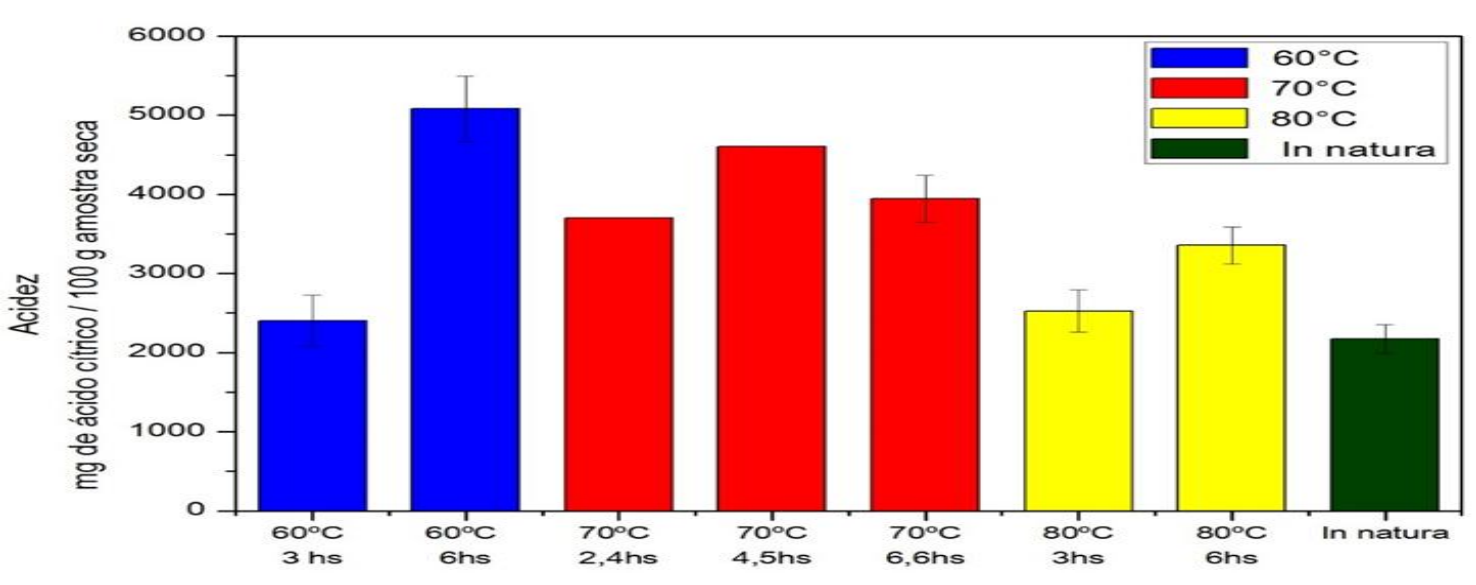

Os resultados obtidos para a Acidez (ATT) estão expressos na Figura 4. Verificou-se que os teores de ácido cítrico nas amostras foram em geral superiores aos obtidos na microalga in natura. Observou-se que nas temperaturas de $60^{\circ} \mathrm{C}$ e $80^{\circ} \mathrm{C}$ ocorreu um aumento na acidez da amostra quando o tempo foi elevado de 3 para 6 horas, sendo mais expressivo na primeira temperatura. Já na temperatura de $70^{\circ} \mathrm{C}$ também houve tal aumento, porém o mesmo foi limitado, pois quando se eleva o tempo de 4,5 horas para 6,6 horas há uma leve degradação.

Figura 5 - Teor de Ficocianina da Spirulina após as secagens e in natura

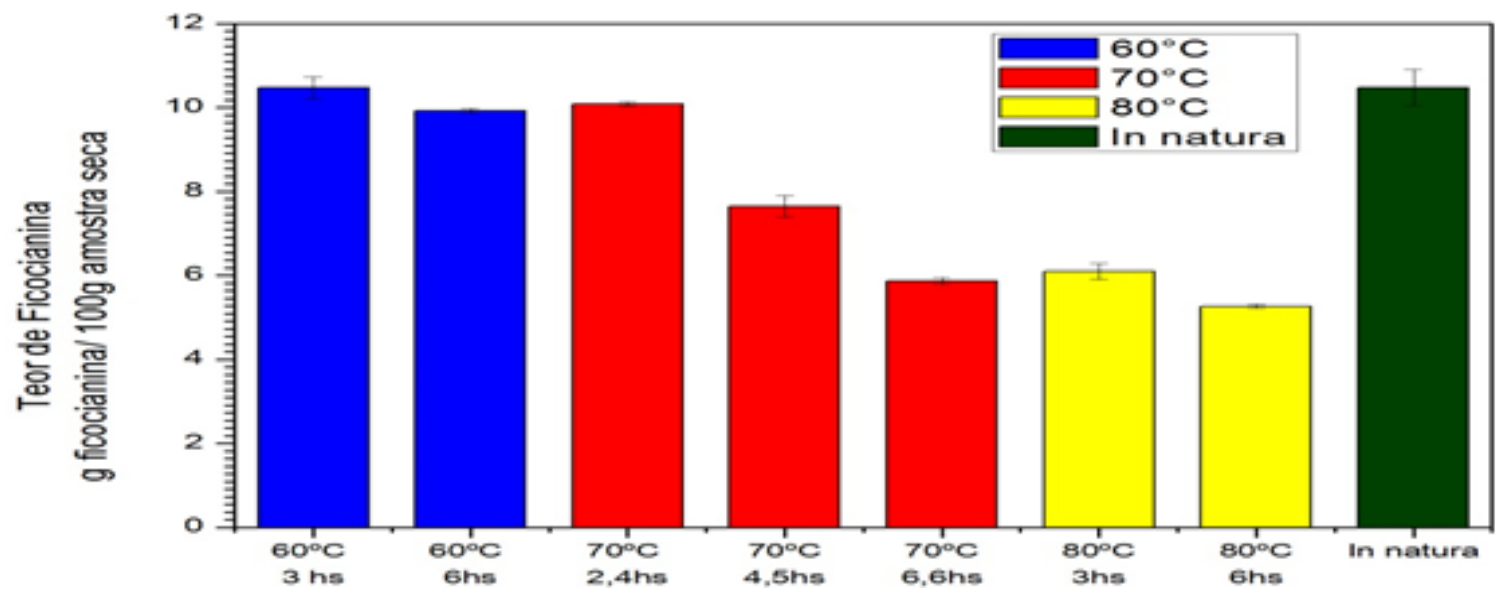

Os teores de ficocianina (TF) obtidos nos experimentos são mostrados na Figura 5. Verificou-se que o aumento da temperatura impactou negativamente esse composto durante a secagem, já que o mesmo apresentou teores próximos aos do material in natura nos experimentos realizados à $60^{\circ} \mathrm{C}$ e que, a partir de $70^{\circ} \mathrm{C}$, há uma degradação súbita de ficocianina, chegando a atingir praticamente metade do valor inicial. Tal comportamento foi reportado por Doke (2005) que verificou que a ficocianina é um composto altamente 
termossensível. O tempo também ocasionou um comportamento semelhante em todas as temperaturas analisadas: quanto maior o tempo de secagem, menores os teores de ficocianina.

\section{CONCLUSÕES}

A partir da análise dos resultados obtidos no presente trabalho, concluiu-se que a secagem por Janela de Refratância se mostrou uma metodologia bastante efetiva tanto para a remoção de umidade da microalga Spirulina platensis quanto para os seus compostos bioativos já que não afetou drasticamente os mesmos, desde que realizada em condições específicas. Os teores de fenólicos e flavonoides apresentaram um aumento em relação ao resíduo in natura. Em ambos, a temperatura de $70^{\circ} \mathrm{C}$ e o tempo de $6,6 \mathrm{~h}$ permitiu os melhores resultados. Já o ácido cítrico obteve um acréscimo em todas as condições analisadas, enquanto que a ficocianina se mostrou visivelmente termossensível, impactada pela temperatura e tempo de secagem. Dentre as condições experimentais analisadas pode-se afirmar que secar a Spirulina à $70^{\circ} \mathrm{C}$ por 6,6 horas, foi a melhor combinação de fatores para obter-se um teor de compostos bioativos satisfatório, um material com baixa umidade e valores adequados de atividade de água.

\section{REFERÊNCIAS}

AOAC - Official Methods of Analysis Association of Official Analytical Chemists. Gaithersburg, MD: Association of Analytical Communities, 1995.

CELESTINO, S.M.C. Princípios de secagem de alimentos. Planaltina, DF: Embrapa Cerrados, 51p, 2010.

CHISM, G. W.; HAARD, N. F. Characteristics of edible plant tissues. Food Chemistry, $3^{\text {a }}$ Ed., p. 943-1011. New York; Marcel Dekker, Inc, 1996.

COSTA, B. R.; RODRIGUES, M. C. K.; SILVA, F. R.; POHNDORF, R. S.; LARROSA, A. P.; PINTO, L. A. A. Optimization of spirulina sp. Drying in heat pump: effects on the physicochemical properties and color parameters. J. Food Process. Preserv v. 40, p. $934-$ 942, 2015.

DOKE, J. M. An improved and efficient method for the extraction of phycocyanin from Spirulina sp. IJFE, v. 1, p. 1-13, 2005.

MANI, U. V., IYER, U.M., DHRUV, S. A. Therapeutic utility of Spirulina. Gershwin ME, Belay A (eds) Spirulina in human nutrition and health, p. 71-100, 2008.

NINDO, C.I.; POWERS, J.R.; TANG, J. Influence of Refractance Window evaporation on quality of juices from small fruits. $L W T$, v.40, p.1000-1007, 2007.

SINGLETON, V. L.; ROSSI, J. A. Colorimetry of total phenolics with phosphomolibidic phosphotungistic acid Reagents. Am. J. Enol. Vitic, v. 16, p. $144-158,1965$.

ZHISHEN, J.; MENGCHENG, T.; JIANMING, W. The determination of flavonoid contents in mulberry and their scavenging effects on superoxide radicals. Food Chemistry, v. 64, p. 555 $-559,1999$.

ZOTARELLI, M.F.; CARCIOFI, B.A.M.; LAURINDO, J.B. Effect of process variables on the drying rate of mango pulp by Refractance Window. Food Res. Int., v.69, p.410-417, 2015. 